\title{
ЭНДОМЕТРИОЗ: ПОИСК ФАРМАТЕРАПЕВТИЧЕСКОГО КОМПРОМИССА
}

\author{
Н.Ф. ЗАХAPEHKO \\ К.мед.н., старший научный \\ сотрудник Института педиатрии, \\ акушерства и гинекологии \\ НАМН Украины, заведующая \\ отделением гинекологии \\ Киевской городской \\ клинической больницы №9
}

\section{H.В. КОСЕЙ}

д.мед.н., главный научный сотрудник отделения эндокринной гинекологии Института педиатрии, акушерства и гинекологии НАМН Украины

\section{Л.М. КОЛОМИЕЦ} научный медицинский редактор ИД «Трилист»

\section{ПОЧЕМУ МЫ ВНОВЬ ГОВОРИМ ОБ ЭНДОМЕТРИОЗЕ?}

Уже много лет эндометриоз, без преувеличения, представляет собой предмет пристального внимания клиницистов. Это обусловлено тем, что данное заболевание входит в тройку лидеров патологий женской половой системы, уступая лишь воспалительным заболеваниям придатков и миоме матки. По оценкам различных авторов, частота эндометриоза у женщин репродуктивного возраста составляет от 5 до 10\% и достигает 15-30\% среди пациенток с первичным или вторичным бесплодием [1, 2]. Усугубляет положение тот фракт, что эндометриоз не имеет «популяционной тропности» и поражает наиболее активную часть женской популяции, т.е. встречается преимущественно у женщин репродуктивного возраста вне зависимости от этнической и социальной принадлежности.

Помимо того, что эндометриоз является грозной причиной бесплодия, симптомы этого заболевания также оказывают выраженное влияние на фризический, психологический и социальный комфорт женского населения. Как известно, доминирующим проявлением эндометриоза является неспецифический симптом - боль в различных ее вариантах (дисменорея, диспареуния, дизурия, дисхезия, абдоминальная, хроническая тазовая боль). Дополнительно ситуацию усугубляет хроническое прогрессирующее течение заболевания. При этом у многих пациенток с эндометриозом может вообще не быть каких-либо симптомов. Посимптомная же диагностика эндометриоза затруднительна, поскольку его проявления изменчивы и часто совпадают с признаками других заболеваний. Имеются данные, что правильный диагноз пациенткам, страдающим эндометриозом, устанавливают в среднем через 8,3 года после первого обращения с соответствующими жалобами [9].

Поэтому в Руководстве по ведению пациенток с эндометриозом Королевского колледжа акушеров-гинекологов Великобритании (2006) указывается, что каждый акушер-гинеколог должен проявлять клиническую настороженность в отношении возможного наличия эндометриоза у женщины, особенно если она молодая и жалуется на длительно существующую боль, не связанную с первичной дисменореей. При этом следует учитывать наличие фракторов, которые повышают вероятность эндометриоза, и помнить о его атипичных формах [2].

\section{ПРОСТО ЛИ ЛЕЧИТЬ?}

Поскольку этиология эндометриоза до конца не изучена, терапия заболевания неспецифична и направлена на уменьшение болевого синдрома и устранение субстрата эндометриоза - очагов. Лечение эдометриоза до наступления беременности или вплоть до периода менопаузы должно отвечать трем основным критериям: эффективности, безопасности и хорошей переносимости при длительном использовании.

\section{О стандартах}

В медицине практически постоянно происходит переоценка ценностей, в т.ч. и стандартов фармакотерапии. Принципы лечения эндометриоза тоже не остались непоколебимыми Так, еще весьма недавно стандартом в лечении эндометриоза считались агонисты гонадотропных рилизинг-гормонов (аГнРГ) в связи с их высокой эфрфективностью. Однако их применение сопровождается симптомами дефицита эстрогенов: приливами жара, сухостью во влагалище, снижением либидо. Особенно тревожно для врача то, что прием аГнРГ может привести к ятрогенному снижению минеральной плотности костной ткани (МПКТ) в связи с дефрицитом эстрогенов. Это обусловливает повышение риска остеопороза и требует терапии прикрытия эстрогенами. И хотя терапия прикрытия снижает риск деминерализации костной ткани при использовании аГнРГ, однако повышает стоимость лечения [9].

Поэтому в настоящее время подходы к принципам фрармакотерапии эндометриоза пере сматриваются. В частности, клиническое практическое руководство Канадской ассоциации акушеров-гинекологов (2010) [3] предлагает усовершенствованный алгоритм терапии тазовой боли, связанной с эндометриозом (уровень доказательности IA ${ }^{1}$ ) (схема).

Подавление овариальной функции с помощью комбинированных оральных контрацептивов (KOK) в течение 6 мес уменьшает болевые ощущения при эндометриозе. Женщинам, которые не отвечают на терапию КОК или прогестинами или же у которых вновь появились симптомы заболевания после первичной терапии, следует назначать аГнРГ (IA). Руководство Канадской ассоциации акушеровгинекологов и консенсус Рабочей группы по тазовой боли и эндометриозу Медицинской школы Калифорнийского университета [3, 4]

${ }^{1}$ Доказательства получены как минимум из одного рандомизированного контролируемого исследования и доказательная база достаточна для того, чтобы рекомендовать это мероприятие. 
в настоящее время рассматривает эту группу препаратов как средства второй линии терапии эндометриоза. При этом их обязательно следует применять под прикрытием гормональной терапии, которая вне зависимости от выбранного препарата должна содержать 1 мг 17ß-эстрадиола или его адекватный эквивалент.

\section{Новый взгляд на прогестины}

Поскольку эстрогены, входящие в КОК, стимулируют рост эндометриоидной ткани, у пациенток с диагностированным эндометриозом рациональным является применение только прогестиновых препаратов - пероральных, внутримышечных или подкожных форм (IA). Данная группа препаратов может рассматриваться в качестве первой линии терапии. Синтетические гормоны с прогестероноподобным действием аналогично угнетают функциональную активность по оси «Гипофииз-яичники» и подавляют пролиферативные процессы в эндометрии.

Однако не все прогестины зарекомендовали себя с лучшей стороны при устранении проявлений эндометриоза. Поскольку гестагены бывают производными разных стероидов (19-нортестостерона, прогестерона), то они существенно различаются по эффрективности. Более новые типы гестагенов селективно связываются с рецепторами прогестерона, что позволяет свести к минимуму и даже исключить андрогенные, эстрогенные и глюкокортикоидные побочные эфрфекты (Kohler G., Faustmann T.A., Gerlinger C. et al., 2010). Производные 19-нортестостерона сочетают выраженное прогестагенное влияние на эндометрий с низкой андрогенной, эстрогенной и глюкокортикоидной активностью. Наиболее приемлемым представителем таких препаратов является диеногест, сочетающий в себе типичные особенности 19-нортестостерона и производных прогестерона.

Диеногест - единственный гестаген для приема внутрь, изученный для лечения эндометриоза в специальной программе клинических исследований. В ходе ряда испытаний этого прогестина была изучена его клиническая эффективность при наличии пролиферативных заболеваний репродуктивной системы. В суточной дозе, равной 2 мг, он в сравнении с плацебо показал превосходящую эфффективность в уменьшении тазовой боли, обусловленной эндометриозом [7]. Исследования продемонстрировали его антиандрогенную активность в отличие от других производных 19-нортестостерона, имеющих андрогенные свойства. Диеногест также не обладает минералокортикоидной или глюкокортикоидной активностью in vivo. Кроме того, установлено его антипролиферативное влияние, благодаря которому эндометриоидные очаги исчезают или значительно

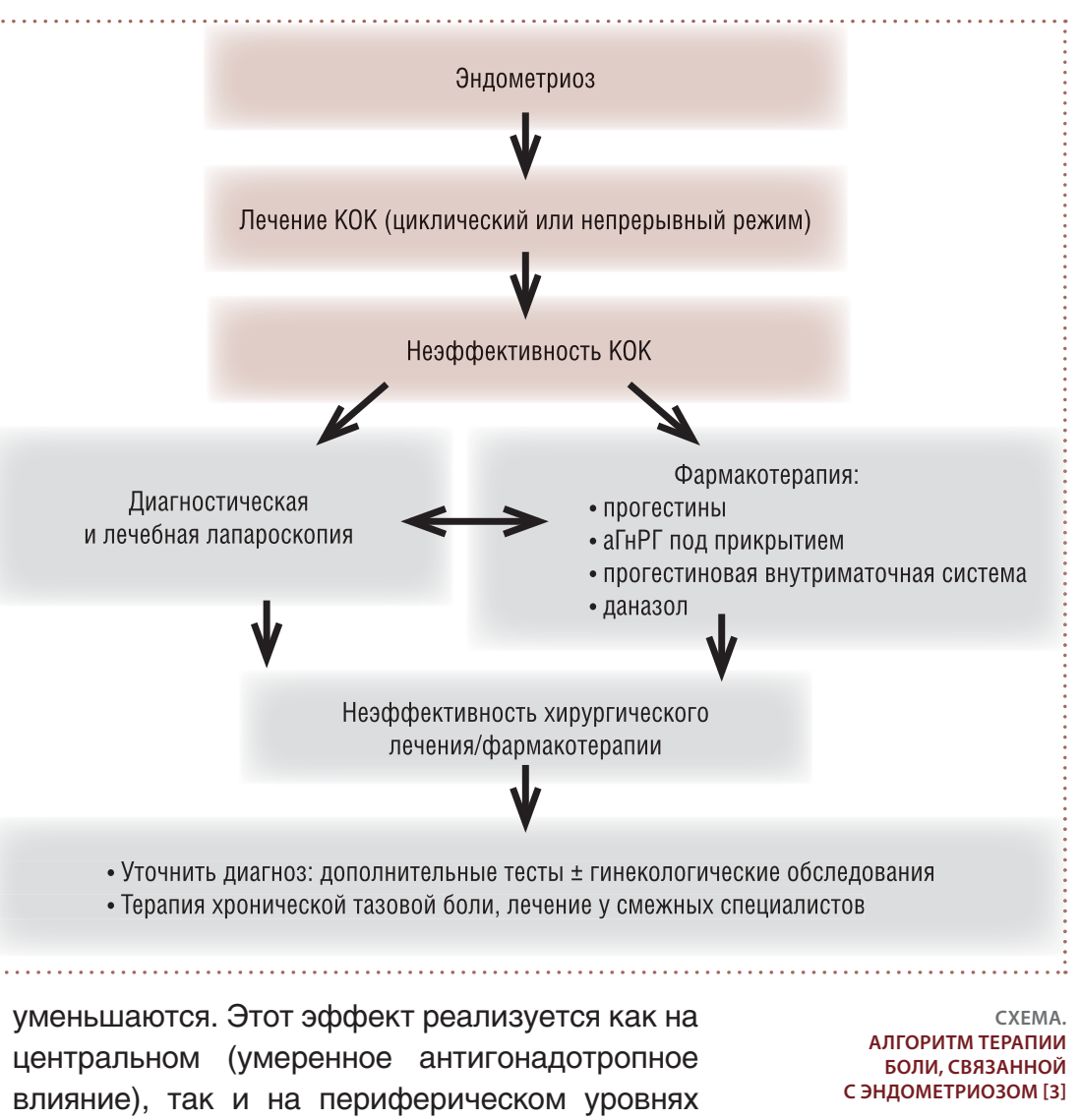
(атрофия эутопического эндометрия и эктопированных эндометриоидных очагов) [9].

Диеногест отличается от других производных 19-нортестостерона наличием цианометильной группы вместо этинильной. Именно поэтому данный препарат сочетает в себе полезные свойства производных 19-нортестостерона и прогестерона. С другими производными 19-нортестостерона его объединяют мощное прогестагенное влияние на эндометрий, небольшой период полувыведения (9-10 ч) и высокая биодоступность (при приеме внутрь > 90\%) (Sasagawa S., Shimizu Y., Kami H. et al., 2008). Прогестероновые свойства диеногеста включают хорошую переносимость, очевидный антиандрогенный эффект и умеренное ингибирующее действие на секрецию гонадотропинов.

Антиандрогенная активность - важная характеристика диеногеста. Эндометриоз с современных позиций рассматривают как эндокринно-активный субстрат, способный осуществлять автономную продукцию эстрогенов. Поэтому антиандрогенное влияние диеногеста является патогенетически значимым его свойством. В ходе клинических исследований было доказано, что этот гестаген способен активно влиять на клинические проявления эндометриоза как опосредованно - через подавление секреции эстрадиола яичниками, так и непосредственно на эндометриоидные гетеротопии, практически не влияя на метаболические процессы. Чрезвычайно важным является и то, что для 


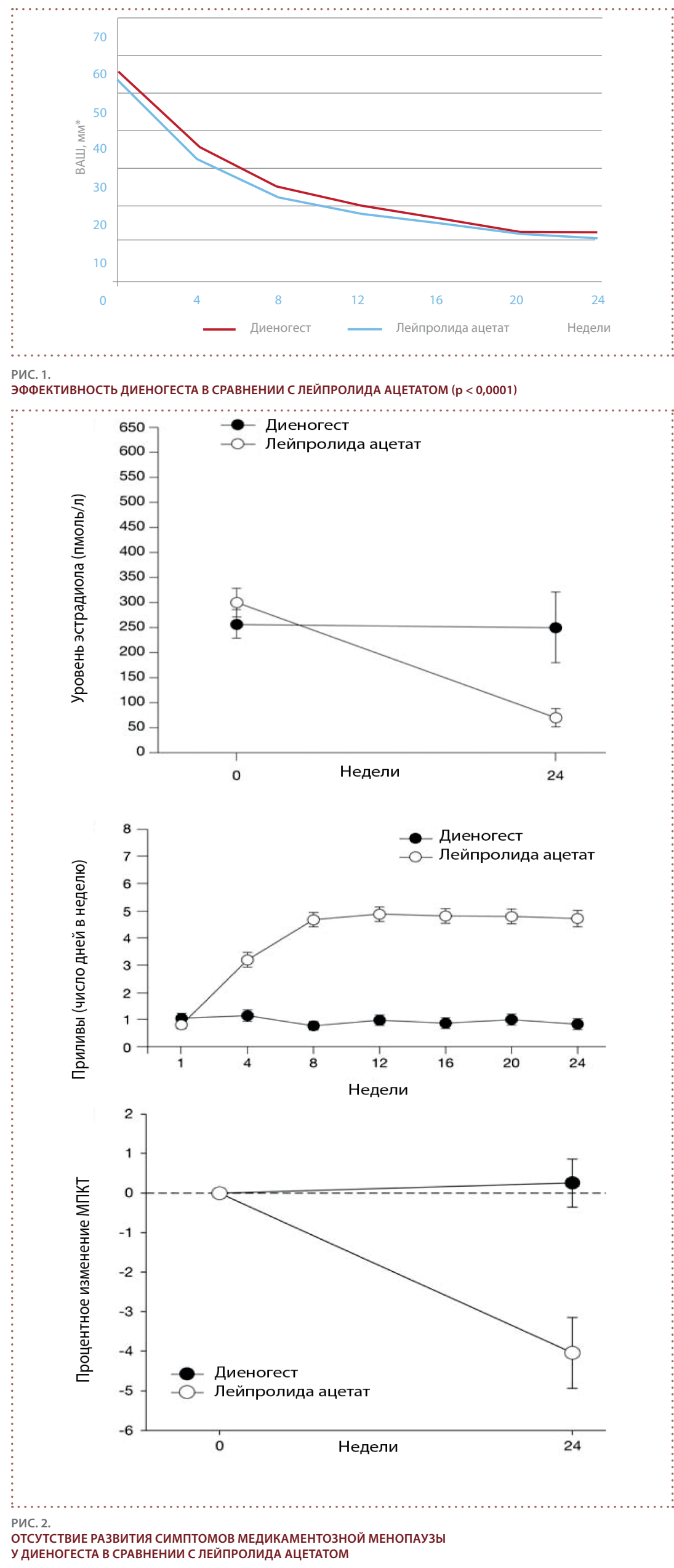

достижения этих эффректов необходима более низкая терапевтическая доза, чем при использовании ряда других прогестагенов.

Как уже упоминалось, диеногест в дозе 2 мг статистически значимо уменьшает объем эндометриоидных очагов. В клинических исследованиях были получены дополнительные сведения об эффективности диеногеста 2 мг в уменьшении объема эндометриоидных поражений. В открытом клиническом исследовании длительностью 24 нед применение диеногеста в дозе 1 мг 2 раза в сутки привело к исчезновению очагов эндометриоза у $66,7 \%$ пациенток (по данным повторной лапароскопии). Выраженное улучшение отмечено у 80,4\% женщин, отсутствие явного эфрфекта - у 19,6\% (Sasagawa S., Shimizu Y., Kami H. et al., 2008).

Было проведено множество экспериментальных и клинических исследований, касающихся эффрективности различных доз диеногеста, его влияния на липидный и углеводный обмен, эндометриоидные гетеротопии. В ряде исследований, в которых сравнивали эфффективность и приемлемость аналогов гонадолиберина и диеногеста, выявили перспективность применения диеногеста при эндометриозе, особенно у молодых женщин. Так, C. Moore et al. (1999) приводят данные о 267 пациентках с эндометриозом, которые получали лечение диеногестом в течение 6 мес. Эффрективность диеногеста у этих больных была сравнима с даназолом и аГнРГ, однако безопасность и толерантность были значительно выше. Результаты эндоскопии через 6 мес лечения объективно свидетельствовали о полном исчезновении эндометриоидных гетеротопий или их частичной ремиссии у $85 \%$ больных. При дальнейшем наблюдении в течение $6 \mathrm{mес}$ рецидивы заболевания наблюдались только у $7,7 \%$ женщин. Приемлемость диеногеста была высокой. Системные побочные эфрфекты проявлялись нечасто (10,5\%) в виде тошноты, головной боли, депрессии. При этом многие женщины отметили улучшение состояния кожи, уменьшение акне, гирсутизма. Не было выявлено существенных изменений артериального давления, веса, функций печени, липидного спектра крови и массы тела.

\section{Диеногест и трипторелин}

В ряде исследований сравнивали эфффективность аГнРГ и прогестагенов в лечении эндометриоза. Так, американские клиницисты M. Cosson, D. Querleu, J. Donnez et al. (2002) провели многоцентровое открытое рандомизированное параллельное сравнительное исследование эффективности диеногеста против трипторелина в восстановительном 4-месячном лечении после операции 
ГИНЕКОЛОГИЯ

по поводу эндометриоза с участием женщин со 2-4-й стадией эндометриоза при первичной лапароскопии. В период с июня 1994 по июль 1998 г. 120 пациенток были включены в исследование; 59 из них принимали диеногест в течение 16 нед по 1 мг/сут, 61 - трипторелин по 3,75 мг внутримышечно каждые 4 нед. Пациентки обеих групп были сопоставимы по демографическим и клиническим характеристикам, длительности эндометриоза, результатам оценки по визуально-аналоговой шкале $(\text { ВАШ })^{2}$, показателям шкалы Американского общества изучения фертильности. В результате не было выявлено существенной разницы в эффрективности данных препаратов. Лечение не влияло на массу тела и жизненно важные функции. В итоге исследователи пришли к выводу, что диеногест не уступает по эфффективности трипторелину в восстановительной терапии после операции по поводу эндометриоза. Авторы исследования отметили, что диеногест представляет собой новую терапевтическую альтернативу аГнРГ ввиду лучшего профиля переносимости и безопасности [5].

\section{Диеногест и бусерелин}

Японские клиницисты Медицинской школы при университете Tottori (Tasuku Harada, Mikio Momoeda, Yuji Taketani et al., 2008) сообщают о том, что прогестин диеногест столь же эффрективен, как аГнРГ бусерелин в отношении уменьшения выраженности симптомов эндометриоза и при этом менее интенсивно снижает костную массу. Ученые провели рандомизированное многоцентровое двойное слепое контролируемое исследование с участием 271 женщины на базе 24 исследовательских центров Японии. Участницы (средний возраст 34 года) были рандомизированны на лечение в течение 24 нед диеногестом в дозе $2 \mathrm{mг/}$ сут per os или интраназально бусерелином 900 мкг/сут. Оба препарата были одинаково эффрективны в облегчении межменструальных симптомов - уменьшали абдоминальную боль, люмбаго, боль при дефекации, диспареунию, боль при внутреннем обследовании. Отмечалось также существенное уменьшение фризической боли по шкале Short Form36 Quality of Life (22,2 для диеногеста и 18,5 для бусерелина). Применение диеногеста способствовало меньшему снижению МПКТ к концу исследования (-1,0 против -2,6\%), которое ученые связывают с более высокой концентрацией сывороточного эстрадиола во время лечения этим препаратом. Полученные результаты позволяют предположить, что диеногест может стать новой терапевтической альтернативой для лечения эндометриоза [8].

\begin{tabular}{|c|c|c|c|c|}
\hline \multirow{2}{*}{$\begin{array}{c}\text { Нежелательные } \\
\text { эффекты }\end{array}$} & \multicolumn{2}{|c|}{ Диеногест, 2 мг $(\mathrm{n}=120)$} & \multicolumn{2}{|c|}{ Лейпролида ацетат, 3,75 мг ( $=128)$} \\
\hline & $n$ & $\%$ & $\mathrm{n}$ & $\%$ \\
\hline Головная боль & 15 & 12,5 & 25 & 19,5 \\
\hline Увеличение массы тела & 8 & 6,7 & 5 & 3,9 \\
\hline Депрессия & 6 & 5,0 & 11 & 8,6 \\
\hline Снижение либидо & 5 & 4,2 & 8 & 6,3 \\
\hline Акне & 5 & 4,1 & 6 & 4,7 \\
\hline Алопеция & 4 & 3,3 & 7 & 5,5 \\
\hline Мигрень & 3 & 2,5 & 6 & 4,7 \\
\hline Нарушения сна & 2 & 1,7 & 10 & 7,8 \\
\hline Сухость влагалища & 2 & 1,7 & 9 & 7,0 \\
\hline Приливы & 0 & 0,0 & 9 & 7,0 \\
\hline
\end{tabular}

\section{Диеногест и лейпролида ацетат}

Рандомизированное многоцентровое открытое 24-недельное исследование по сравнению эффрективности и безопасности диеногеста и лейпролида ацетата в лечении обусловленной эндометриозом боли провели немецкие клиницисты T. Strowitzki1, J. Marr, C. Gerlinger et al. (2010). Вошедшие в исследование пациентки были распределены на группу приема диеногеста 2 мг/сут (124 женщины) и группу приема лейпролида ацетата в дозе 3,75 мг внутримышечно каждые 4 недели (128 женщин). Выраженность тазовой боли в начале и в конце исследования оценивали по ВАШ. Безопасность препаратов изучали по побочным эффектам, лабораторным параметрам, МПКТ, костным маркерам и характеристикам кровотечения. Абсолютное снижение боли по ВАШ на 24-й неделе исследования составило 47,5 мм в группе диеногеста и 46,0 в группе лейпролида ацетата, что свидетельствует о сопоставимой эффрективности этих препаратов (рис. 1). В группе диеногеста реже отмечался гипоэстрогенный эффрект (наличие приливов). Также терапия диеногестом реже ассоциировалась с кровотечениями. МПКТ в конце исследования составила $+0,25 \%$ для диеногеста и -4,04\% для лейпролида ( $p=0,0003$ ) (рис. 2). Маркеры костной резорбции были повышены в группе лейпролида, но не в группе диеногеста. Наряду с этим диеногест продемонстрировал более высокий профриль безопасности, нежели лейпролида ацетат (таблица). Авторы исследования пришли к выводу, что лечение ассоциированной с эндометриозом боли диеногестом в дозе 2 мг/сут эквивалентно по эффективности стандартной дозе депо лейпролида ацетата, а по безопасности и переносимости превосходит последний [7].

Таким образом, диеногест как прогестерон с минимальной андрогенной активностью хорошо себя показал в терапии эндометриоза в качестве альтернативы аГнРГ. Это возможно благодаря тому, что он оказывает выраженное прямое ингибирующее действие на пролиферацию эндометриоидных гетеротопий, вызывая почти полную их регрессию, 
оказывает противовоспалительное действие и подавляет неоангиогенез. При этом помимо фрармакотерапевтической активности диеногест обладает более оптимальным просилем безопасности в отличие от аГнРГ и практически не вызывает свойственных данной группе препаратов побочных эффектов.

Результаты указанных в данной статье клинических исследований показали следующее:

при длительном использовании диеногеста наблюдается лишь умеренный гипоэстрогенный эффект, и поскольку препарат не блокирует полностью синтез эндогенных эстрогенов, его прием не вызывает побочных эфрфектов, связанных с гипоэстрогенией (приливов, снижения МПКТ) [7];

с содержание липидов в плазме крови на фоне лечения диеногестом изменяется минимально (Cosson M. et al., 2002);

изменения массы тела при использовании диеногеста (Shimizu Y. et al., 2009);

изменение характера влагалищных кровотечений, являющихся побочным действием прогестинов, снижаются по мере увеличения длительности приема диеногеста в дозировке 2 мг/сутки и не послужили отказом от приема препарата в программе клинических исследований;

эффрективность, профриль безопасности и переносимость диеногеста в дозе 2 мг являются предпочтительными для длительного использования.

Таким образом, учитывая хорошую переносимость, минимальные метаболические эффректы и более низкую стоимость, диеногест может рассматриваться как препарат выбора для лечения эндометриоза.

\section{выводы}

Подводя итоги вышеизложенного, следует еще раз подчеркнуть, что эндометриоз требует тщательной диагностики и адекватного лечения, которое должно быть индивидуальным и учитывать данную клиническую проблему в полном объеме, включая влияние способов ее лечения на качество жизни пациентки. При этом фрармакотерапевтический выбор следует основывать на оптимальной эфффективности, безопасности и переносимости препарата

Последние годы ознаменовались пересмотром стандартов лечения эндометриоза. Полученные результаты рандомизированных клинических исследований свидетельствуют о том, что эфффективность прогестина диеногеста не уступает аГнРГ - стандарту лечения эндометриоза, поскольку при равной эфффективности этих групп препаратов диеногесту не свойственны явления медикаментозной менопаузы.

\section{ЛИТЕРАТУРА}

1. ESHRE guideline for the diagnosis and treatment of endometriosis. June 2007.

2. RCOG Standart: Investigation and Management of Endometriosis. October 2006

3. SOGC Clinical Practice Guideline: Endometriosis: Diagnosis and Management. July 2010.

4. Joseph C. Gambone et al. Consensus statement for the management of chronic pelvic pain and endometriosis: proceedings of an expert-panel consensus process. Chronic Pelvic Pain/Endometriosis Working Group, UCLA Medical School, Los Angeles, California Fertility and Sterility. 2002. Vol. 78, No. 5

5. Cosson M., Querleu D., Donnez J., Madelenat P., Koninckx P., Audebert A., Manhes H. Dienogest is as effective as triptorelin in the treatment of endometriosis after laparoscopic surgery: results of a prospective, multicenter, randomized study. Fertility and Sterility. April 2002, Vol. 77, No. 4.

6. Filicori M., Flamigni C., Cognigni G., Dellai P. Rossella arnone, angela falbo, and maurizio capelli. Comparison of the Suppressive Capacity of Different Depot Gonadotropin-Releasing Hormone Analogs in Women. Journal of Clinicei Endocrinology and Metabolism. 1993. Vol. 17, No. 1.

7. Strowitzki1 T., Marr J., Gerlinger C., Faustmann T., Seitz C. Dienogest is as effective as leuprolide acetate in treating the painful symptoms of endometriosis: a 24-week, randomized, multicentre, open-label trial. Human Reproduction, 2010. Vol. 00 No. 0, 1-9 pp.

8. Tasuku Harada, Mikio Momoeda, Yuji Taketani, Takeshi Aso, Masao Fukunaga, Hiroshi Hagino, Naoki Terakawa. Dienogest is as effective as intranasal buserelin acetate for the relief of pain symptoms associated with endometriosis - a randomized, double-blind, multicenter, controlled trial. Fertility and Sterility. 2008.

9. Леваков С.А., Хамошина М.Б. Эндометриоз: мировой прорыв в медикаментозном лечении. - М.: Редакция журнала Status Praesens, 2012. - 16 c 


\section{$\mathrm{Bl} 3 \mathrm{OH}+\overline{6}$}

\section{Тазовая боль}

Энуометриоз

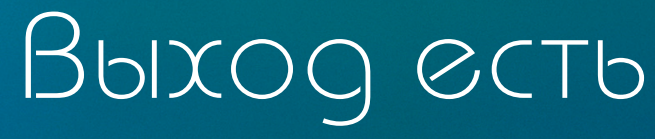

Эфрфективно купирует боль $1,2,3$

0 Достоверно уменьшает очаги эндометриоза ${ }^{1}$

Хорошо переносится при длительном использовании

BA Bayer HealthCare

ТОВ «Байєр»:

04071 м. Київ, вул. Верхній Вал, 4Б

тел: (044) 220-33-00, факс: (044) 220-33-01. www.bayer.ua$$
\text { 2. }
$$$$
\text { нндометріозу. Протипоказання. Венозна тромбоемболія в актив- }
$$
нІи формі; артеріальні або кардіоваскулярні захворювання нині або х наявність в анамнезі; цукровий діабет з ураженням судин; тяжк захворювання печінки нині або іх наявність в анамнезі, поки показники фуункції печінки не повернуться до нормальних значень; пухлини печінки нині або в анамнезі: відомі або підозрювані злоякісн пухлини, залежні від статевих гормонів: вагінальна кровотеча нез'ясованої етіології; підвищена чутливість до діючої речовини або до будь-якого із компонентів препарату. Спосіб застосування та дози. Візан приймають по 1 таблетці щодня, запиваючи невеликою

кіль-кістю рідини, не роблячи перерви у застосуванні препарату.

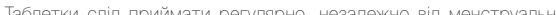

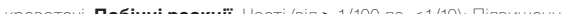
маси тіла, пригнічений настрій, порушення сну, нервозність, зни

ження лібідо, зміни настрою, головний біль, мігрень, нудота, біль у животі, метеоризм, здуття черевноі порожнини, блювання, акне, алопеція, біль у спині, дискомфорт у молочних залозах кіста яєчників, припливи жару, маткові/вагінальні кровотечі, в Т.4. кровомазання, астенія, подразливість. Нечасті (від $\geq 1 / 1000$ до <1/100): анемія, зниження маси тіла, пілвищений апетит, занепокоєння депресія, лабільність настрою, порушення вегетативної регуляції. розсіяна увага, сухість очей, дзвін у вухах, неспецифрічні циркуляторні розлади, посилене серцеоитяя, ппотензія, диспное, діарея запор, дискомфорт у черевній порожнині, запалення шлунковоостаннього перегляду інструкції: 06.01.2011.

Детальна інформація про препарат міститься в інструкції для медичного застосування

1. Köhler $\mathrm{G}$. et al. A dose-ranging study to determine the efficacy and safety of 1,2 , and $4 \mathrm{mg}$ ofdienogest daily for endometriosis. International Journal of Gynecology and Obstetics 2010,108, pp. 21-25.

2. T. Strowitzki et al. Dienogest is as effective as leuprolide acetate in treating the painful symptoms of endometriosis: a 24-week, randomized, multicentre, open-label 